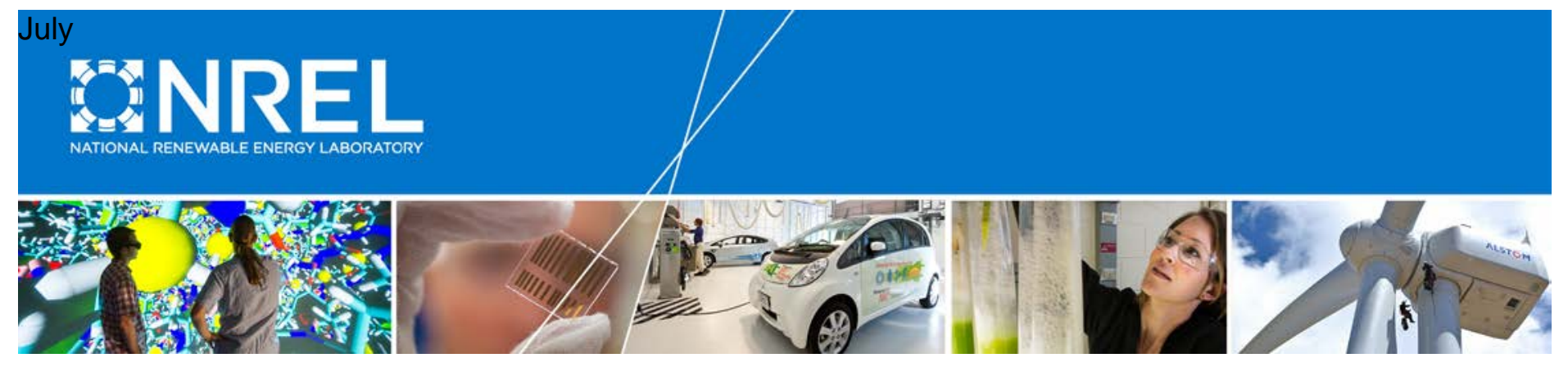

\title{
Economy and Emissions Impacts from Solazyme Fuel in UPS Delivery Vehicles
}

Kenneth Kelly and Adam Ragatz National Renewable Energy Laboratory

NREL is a national laboratory of the U.S. Department of Energy Office of Energy Efficiency \& Renewable Energy Operated by the Alliance for Sustainable Energy, LLC

This report is available at no cost from the National Renewable Energy Laboratory (NREL) at www.nrel.gov/publications.

Technical Report

NREL/TP-5400-68896

August 2018 


\section{Economy and Emissions Impacts from Solazyme Fuel in UPS Delivery Vehicles}

\author{
Kenneth Kelly and Adam Ragatz \\ National Renewable Energy Laboratory
}

\section{Suggested Citation}

Kelly, Kenneth, and Adam Ragatz. 2018. Economy and Emissions Impacts from Solazyme Fuel in UPS Delivery Vehicles. Golden, CO: National Renewable Energy Laboratory. NREL/TP-5400-68896. https://www.nrel.gov/docs/fy180sti/68896.pdf.
National Renewable Energy Laboratory 15013 Denver West Parkway Golden, CO 80401

303-275-3000 • www.nrel.gov
NREL is a national laboratory of the U.S. Department of Energy Office of Energy Efficiency \& Renewable Energy Operated by the Alliance for Sustainable Energy, LLC

This report is available at no cost from the National Renewable Energy Laboratory (NREL) at www.nrel.gov/publications.

\section{Technical Report}

NREL/TP-5400-68896

August 2018

Contract No. DE-AC36-08GO28308 


\section{NOTICE}

This work was authored by the National Renewable Energy Laboratory, operated by Alliance for Sustainable Energy, LLC, for the U.S. Department of Energy (DOE) under Contract No. DE-AC3608GO28308. Funding provided by USDOE Office of Energy Efficiency and Renewable Energy (EERE), Vehicle Technologies Office (EE-3V). The views expressed in the article do not necessarily represent the views of the DOE or the U.S. Government.

This report is available at no cost from the National Renewable Energy Laboratory (NREL) at www.nrel.gov/publications.

U.S. Department of Energy (DOE) reports produced after 1991 and a growing number of pre-1991 documents are available free via www.OSTI.gov. 


\section{List of Acronyms and Abbreviations}

$\mathrm{CO}_{2}$

HHDDT

HTUF

HWFET

LHV

$\mathrm{NO}_{\mathrm{x}}$

NREL

ReFUEL

SCR

ULSD carbon dioxide

Heavy Heavy-Duty Diesel Truck

Hybrid Truck Utility Forum Class

U.S. EPA Highway Fuel Economy Test

lower heating value

nitrogen oxides

National Renewable Energy Laboratory

Renewable Fuels and Lubricants

selective catalyst reduction

ultra-low sulfur diesel 


\section{Table of Contents}

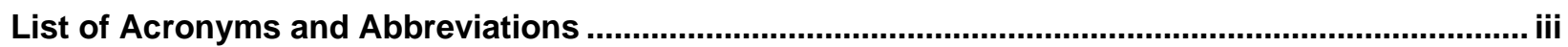

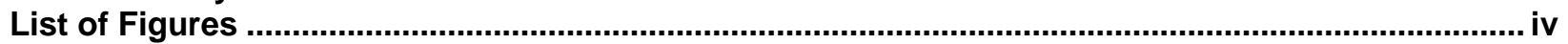

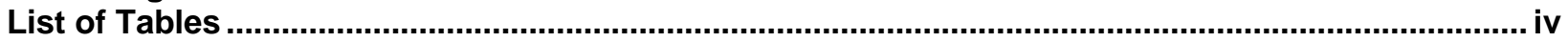

Background

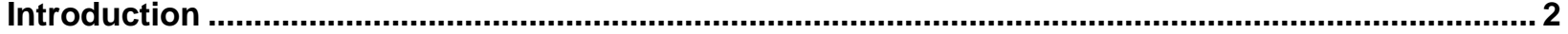

Approach

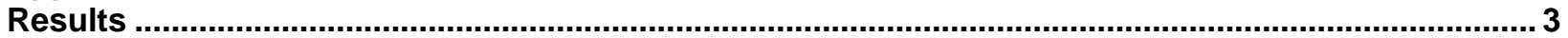

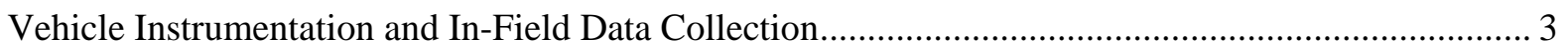

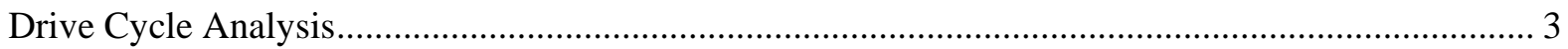

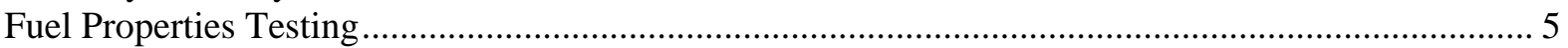

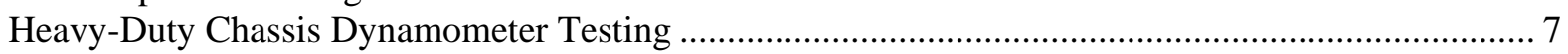

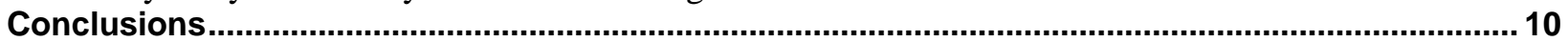

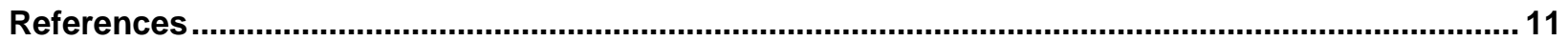

\section{List of Figures}

Figure 1. UPS package car (left) and day-cab tractor (right) ............................................................... 1

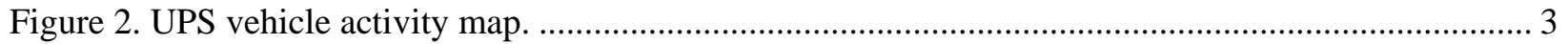

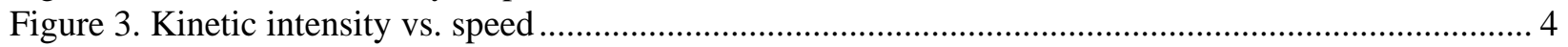

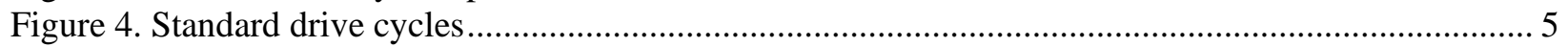

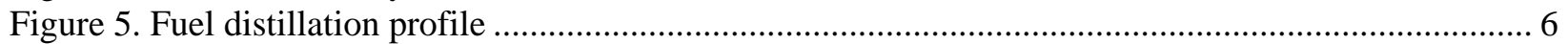

Figure 6. Fuel density and lower heating values compared with reference values................................... 7

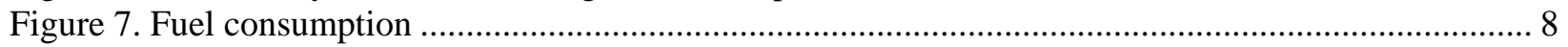

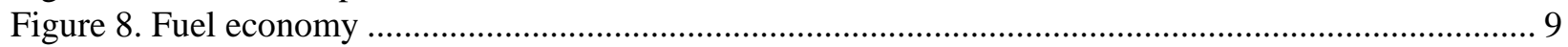

Figure 9. Relative differences in $\mathrm{CO}_{2}$ emissions, fuel consumption, and fuel economy among the cycles . 9

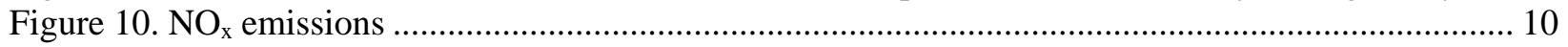

\section{List of Tables}

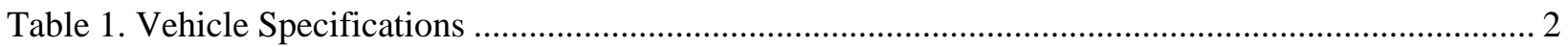

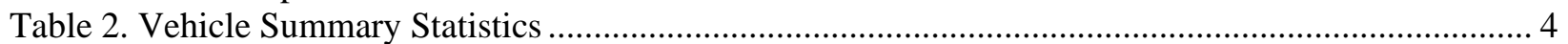

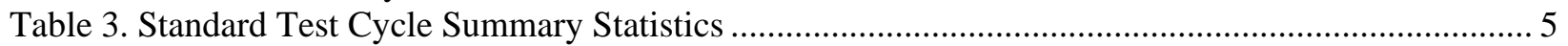

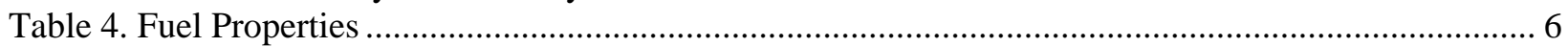




\section{Background}

UPS is one of the largest users of renewable diesel in the world. In 2015, UPS announced its intention to purchase up to 46 million gallons of renewable fuels over three years (UPS 2015). Part of that commitment to renewable fuels included renewable diesel supplied by Solazyme. Renewable diesel is considered a "drop-in" replacement for petroleum diesel and does not require any modifications to existing trucks or equipment. Renewable diesel is held to the same standards as conventional fuel and must comply with ASTM International Standard D975 for diesel fuel oil.

Two categories of vehicles were investigated during a fleet evaluation. The first was the package car, shown on the left in Figure 1. All package cars for this in-field evaluation were model P100D and were equipped with Cummins ISB diesel engines on a Freightliner chassis. The second vehicle category was the day-cab tractor, shown on the right in Figure 1. The day-cab tractors had various engine and chassis makes, but all were class 7-8 and used for regional haul operations. The vehicle specifications are listed in Table 1.

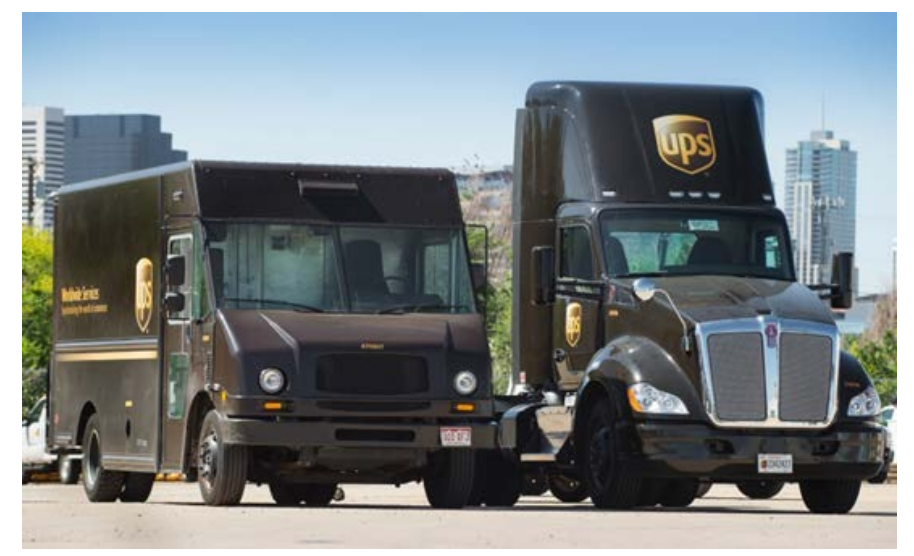

Figure 1. UPS package car (left) and day-cab tractor (right)

Photo by Dennis Schroeder, NREL 34441

In total, 12 vehicles (six package cars and six day-cab tractors) were instrumented for real-world data collection. Data were collected from April 20, 2015, to May 8, 2015. Drive cycle analysis was then used to select appropriate standard test cycles for further evaluation on the heavy-duty chassis dynamometer at the National Renewable Energy Laboratory's (NREL's) Renewable Fuels and Lubricants (ReFUEL) Laboratory. 
Table 1. Vehicle Specifications

\begin{tabular}{lll}
\hline & Package Cars & Tractors \\
\hline Chassis Make & Freightliner Custom Chassis & NA \\
Chassis Model & MT45 & NA \\
Vehicle Make & Utilimaster & Kenworth \\
Vehicle Model & P70D & T680 \\
Vehicle Model Year & 2009 & 2015 \\
GVWR & 15,200 & 34,700 \\
Engine Make & Cummins & PACCAR \\
Engine Model & ISB 6.7-200 HP @ 2,400 RPM; 2,600 & MX-13 \\
Engine Model Year & 2009 & 2015 \\
Transmission Make & Allison & Eaton \\
Transmission Model & 1000 HS Automatic & FAO-16810S-EP3 \\
Rear Axle Ratio & 3.91 & 2.69 \\
\hline
\end{tabular}

\section{Introduction}

NREL's Commercial Vehicle Technologies Team analyzes near-term advanced technologies and provides unbiased performance data to potential vehicle customers, equipment manufacturers, and the research and development community at large. Clean Cities brings together stakeholders in the public and private sectors to deploy alternative and renewable fuels that help advance the nation's economic, environmental, and energy security by reducing petroleum consumption in transportation. Together, as part of a joint effort, a team was assembled to instrument, collect, and analyze real-world drive cycle data from six package delivery cars and six day-cab tractors operating in the Houston area, followed by further fuel economy and emissions analysis at NREL's ReFUEL Laboratory. The goal of this work was to better understand what fuel economy and emissions impacts could arise from switching a fleet of vehicles from conventional petroleum to synthetic renewable diesel.

\section{Approach}

The technical approach for this project follows the general approach for conducting fleet evaluations described above. The UPS Solazyme fuel evaluation included:

- Vehicle instrumentation and in-field data collection

- Drive cycle analysis to determine the most representative standard cycles

- Fuel properties testing

- Heavy-duty chassis dynamometer testing of conventional diesel and Solazyme renewable diesel to determine fuel economy and emissions impacts. 


\section{Results}

\section{Vehicle Instrumentation and In-Field Data Collection}

Six package cars and six day-cab tractors were selected for instrumentation at a Houston-area UPS depot. Selected vehicles were equipped with Isaac DRU900/908 data recorders on April 17, 2015. The devices were configured to watch for over 100 public on-board diagnostic parameters on the vehicle controller area network bus. Not all parameters were reported, but typically over 50 parameters are recorded each second, including vehicle speed, transmission gear, engine fuel rate and air flow, driver demanded and estimated output torque, and various temperatures and pressures throughout the engine and aftertreatment. In addition to controller area network data, the devices also collected 1-Hz global positioning system location and speed information. The loggers remained on the vehicles until May 8, 2015, capturing three full weeks of vehicle operation. Figure 2 shows the collected global positioning system information from both sets of vehicles with a closeup of the Houston metro area on the right.

\section{Blue - Regional Tractor Trailers}

\section{Red - Package Cars}
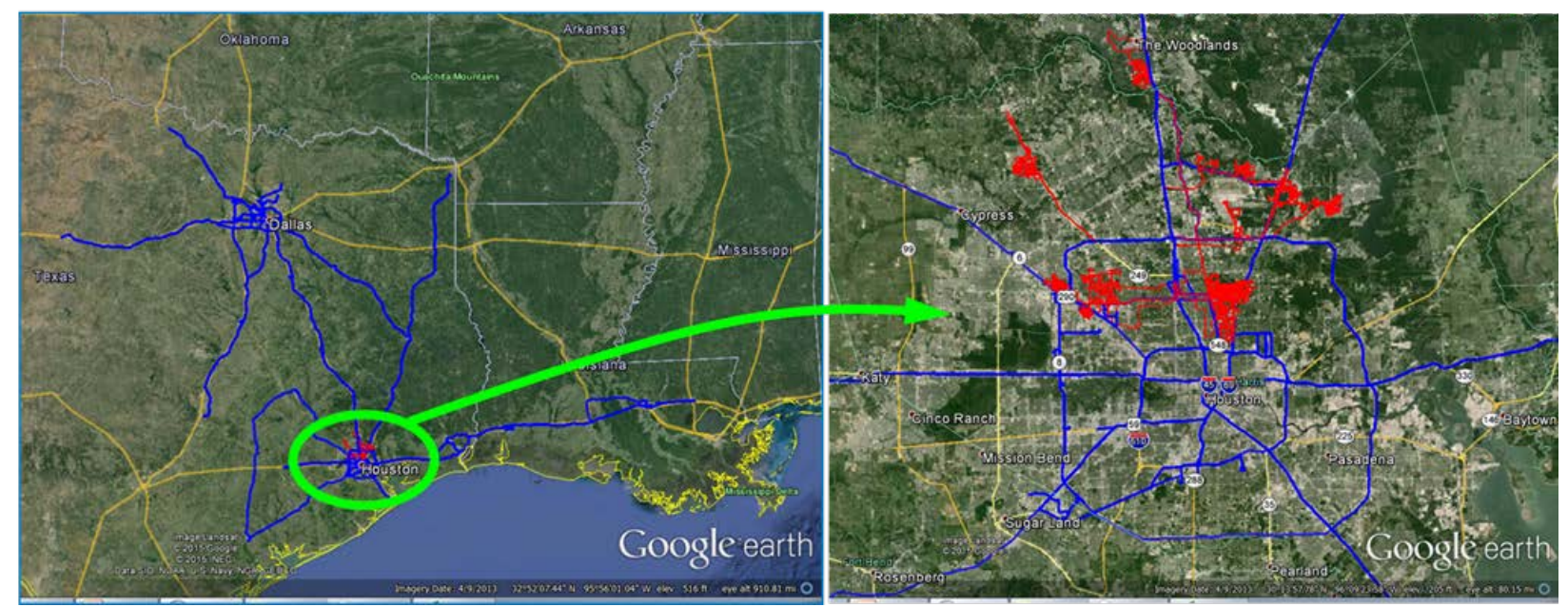

Figure 2. UPS vehicle activity map

Images from Google Earth

\section{Drive Cycle Analysis}

The regional haul day-cab tractors travel between major UPS hubs and cover a large area connecting Houston to Dallas, Baton Rouge, Texarkana, Abilene, Austin, and many areas in between. The package cars travel from stop to stop making individual deliveries in dense urban areas. Therefore, this results in two distinctly and vastly different operating behaviors. Summary statistics for the vehicles are shown in Table 2. As expected, the package cars and day-cab tractors differ significantly in average speed and kinetic intensity, a measure of drive cycle aggressiveness. 
Table 2. Vehicle Summary Statistics

\begin{tabular}{|l|c|c|c|c|c|c|c|c|c|c|c|c|c|}
\hline ISAAC Logger \# & 3 & 5 & 12 & 13 & 15 & 17 & 29 & 30 & 32 & 33 & 34 & 35 \\
\hline Truck Number & 147513 & 143085 & 148105 & 147509 & 147431 & 147544 & 274845 & 273701 & 271971 & 274850 & 274835 & 271919 \\
\hline Vehicle Type & Package & Package & Package & Package & Package & Package & Tractor & Tractor & Tractor & Tractor & Tractor & Tractor \\
\hline Total Time [hr] & 58.3 & 75.2 & 55.0 & 62.7 & 65.6 & 69.5 & 199.3 & 11.5 & 182.0 & 104.9 & 205.9 & 106.7 \\
\hline Idle Time [hr] & 9.4 & 15.7 & 11.3 & 9.4 & 10.5 & 12.0 & 10.9 & 0.9 & 28.9 & 6.5 & 12.3 & 12.8 \\
\hline Idle Time [\%] & $16 \%$ & $21 \%$ & $20 \%$ & $15 \%$ & $16 \%$ & $17 \%$ & $5 \%$ & $8 \%$ & $16 \%$ & $6 \%$ & $6 \%$ & $12 \%$ \\
\hline Total Dist [mi] & 1,162 & 1,158 & 766 & 1,143 & 1,355 & 1,354 & 10,703 & 654 & 6,513 & 5,505 & 11,649 & 4,686 \\
\hline Total Work [kWh] & 1,119 & 1,762 & 1,116 & 1,470 & 1,774 & 1,691 & 29,374 & 1,734 & 11,373 & 12,433 & 31,041 & 10,998 \\
\hline Avg Speed [mph] & 19.9 & 15.4 & 13.9 & 18.2 & 20.7 & 19.5 & 53.7 & 57.0 & 35.8 & 52.5 & 56.6 & 43.9 \\
\hline BSFC [g/kWh] & 287 & 259 & 282 & 265 & 258 & 271 & 198 & 209 & 242 & 203 & 195 & 219 \\
\hline Fuel [Gallons] & 98.5 & 140.2 & 96.7 & 119.5 & 140.5 & 140.5 & 1783.5 & 111.2 & 844.9 & 775.2 & 1862.7 & 739.7 \\
\hline Fuel Econ. [mpg] & 11.8 & 8.3 & 7.9 & 9.6 & 9.6 & 9.6 & 6.0 & 5.9 & 7.7 & 7.1 & 6.3 & 6.3 \\
\hline KI [1/mi] & 0.71 & 2.81 & 2.85 & 1.53 & 1.04 & 1.21 & 0.08 & 0.13 & 0.19 & 0.10 & 0.09 & 0.13 \\
\hline
\end{tabular}

Figure 3 shows a graph of kinetic intensity vs. driving average speed (while the vehicle is in motion, excluding stops). The small dots show individual driving days for both types of vehicles, and the larger symbols of the same color show vehicle averages, as well as several standard cycles that were selected for testing. The Heavy Heavy-Duty Diesel Truck (HHDDT), U.S. EPA Highway Fuel Economy Test (HWFET), and SAE J1376 - Commuter cycles were selected for the day-cab tractor testing. The HHDDT, NY Composite, and Hybrid Truck Utility Forum Class 4 (HTUF 4) were selected for the package car. However, only the NY Composite cycle was tested due to a chassis dynamometer component failure.

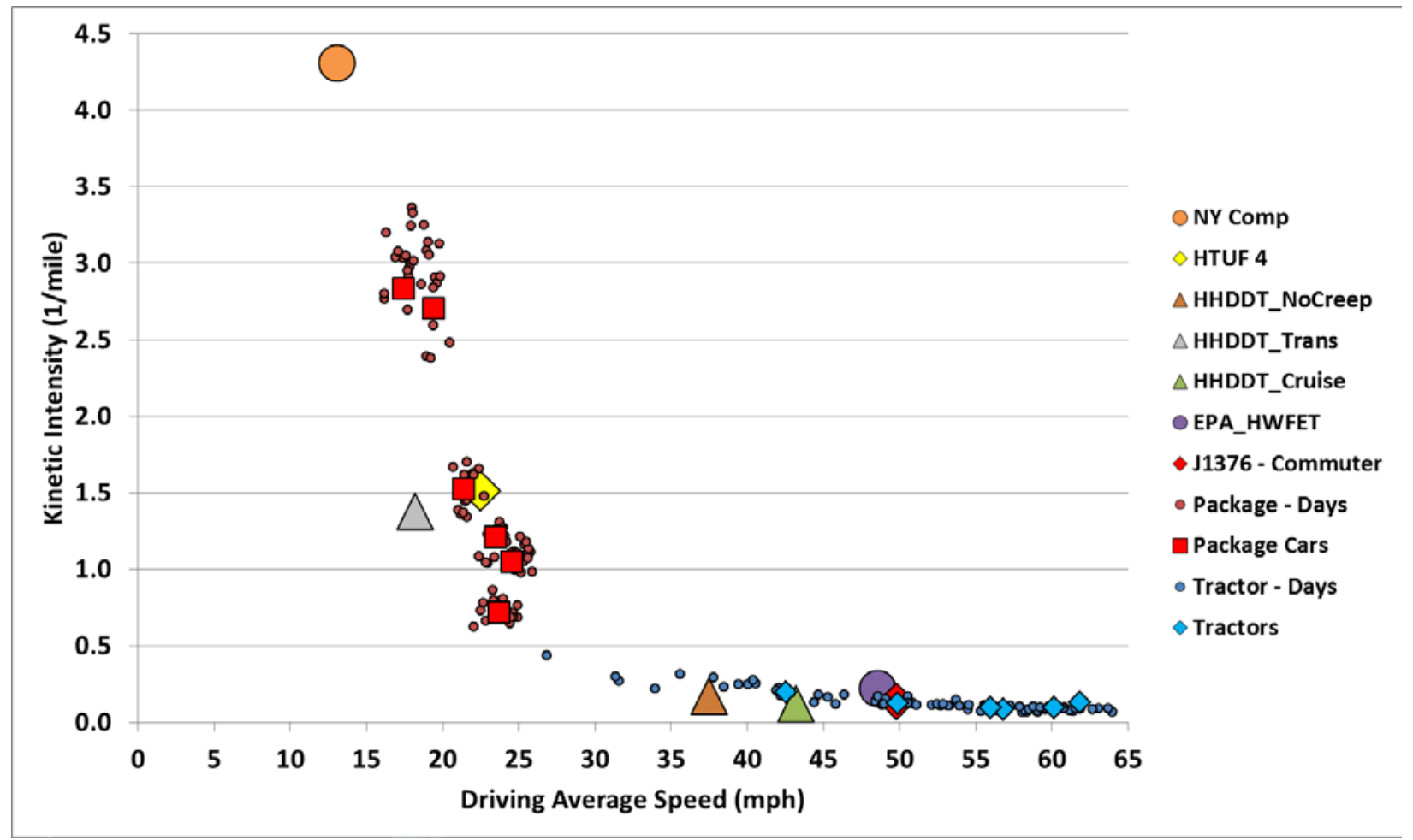

Figure 3. Kinetic intensity vs. speed 
The selected drive cycle time traces are shown in Figure 4, followed by a summary of the statistics in Table 3.
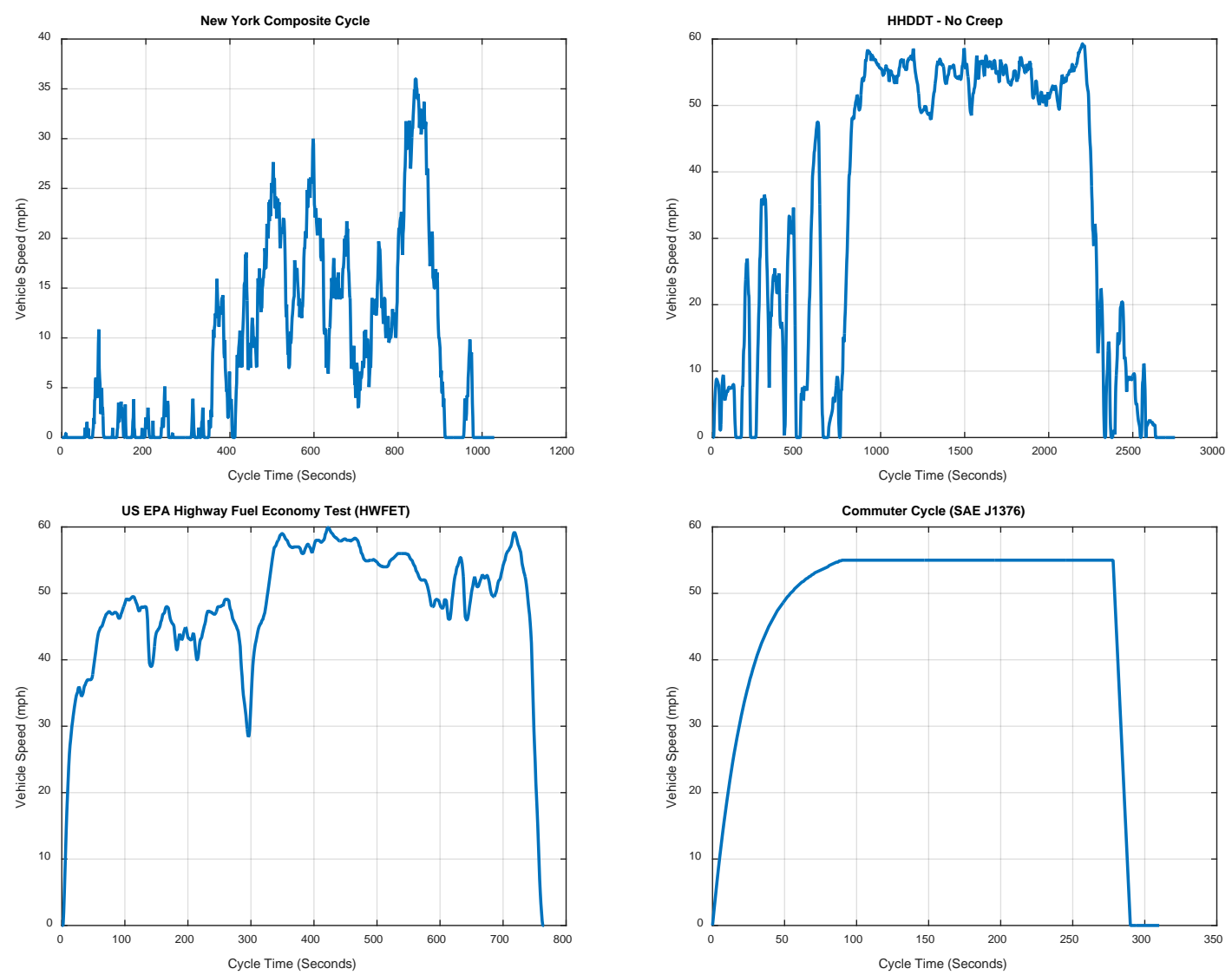

Figure 4. Standard drive cycles

Table 3. Standard Test Cycle Summary Statistics

\begin{tabular}{|c|c|c|c|c|c|c|c|}
\hline \multirow{2}{*}{ Standard Test Cycle } & Cycle Time & Distance & Avg Speed & Avg D Speed & $\mathrm{KI}$ & Stops & Stops \\
\hline & Seconds & $\mathrm{mi}$ & $\mathrm{mph}$ & $\mathrm{mph}$ & $1 / \mathrm{mi}$ & $\#$ & $\# / \mathrm{mi}$ \\
\hline New York Composite Cycle & 1,029 & 2.51 & 8.8 & 13.1 & 4.30 & 20 & 7.98 \\
\hline HTUF Class 4 & 3,336 & 11.17 & 12.1 & 22.5 & 1.51 & 28 & 2.51 \\
\hline HHDDT Cycle Speed Data - Transient Mode & 668 & 2.85 & 15.3 & 18.2 & 1.38 & 4 & 1.40 \\
\hline HHDDT - No Creep & 2,751 & 25.92 & 33.9 & 37.5 & 0.17 & 10 & 0.39 \\
\hline HHDDT - Cruise Mode & 2,083 & 23.07 & 39.9 & 43.2 & 0.12 & 6 & 0.26 \\
\hline US EPA Highway Fuel Economy Test (HWFET) & 765 & 10.26 & 48.2 & 48.6 & 0.22 & 1 & 0.10 \\
\hline Commuter Cycle (SAE J1376) & 310 & 4.00 & 46.3 & 49.8 & 0.14 & 1 & 0.25 \\
\hline
\end{tabular}

\section{Fuel Properties Testing}

Regular summer blend pump fuel was used as the baseline petroleum diesel for the chassis dynamometer tests, and renewable diesel test fuel was supplied directly by Solazyme. Before testing began, fuel samples were extracted from each batch of fuel and sent out for analysis. Some tests, such as density, cloud point, percent biodiesel, and derived cetane, were conducted in-house by NREL's Fuels Performance Group. The remaining tests were conducted at Southwest Research Institute (SwRI). The resulting fuel properties are shown in Table 4. 
Distillation curves are shown in Figure 5. It is worth noting that the Solazyme renewable diesel fuel has slightly higher hydrogen content and mass-based heating value, which will later be shown to reduce tailpipe carbon dioxide $\left(\mathrm{CO}_{2}\right)$ emissions and reduce mass-based fuel consumption. However, Solazyme's lower density is significant enough to result in a lower volume-based heating value, increasing volume-based fuel consumption and reducing fuel economy.

Table 4. Fuel Properties

\begin{tabular}{|c|c|c|c|c|}
\hline \multicolumn{5}{|c}{ SwRI + NREL Fuel Analysis } \\
\hline \multicolumn{2}{|c|}{ Test Method / Test } & Units & ULSD Pump Fuel & Solazyme Fuel \\
\hline D5291 CH & Carbon & wt\% & 85.36 & 83.69 \\
\hline & Hydrogen & wt\% & 13.48 & 14.95 \\
\hline D93 & Flash Point & ${ }^{\circ} \mathrm{F}$ & 144 & 139 \\
\hline & Flash Point & ${ }^{\circ} \mathrm{C}$ & 62 & 60 \\
\hline Density & $\mathrm{g} / \mathrm{cm}^{3}$ & 0.834 & 0.779 \\
\hline Cloud Point & ${ }^{\circ} \mathrm{C}$ & -16.3 & -7.3 \\
\hline \% Biodiesel & $\%$ & 4.61 & 2.59 \\
\hline Lower Heating Value & $\mathrm{J} / \mathrm{g}$ & 42,649 & 43,770 \\
\hline Lower Heating Value & $\mathrm{J} / \mathrm{cm}^{3}$ & 35,556 & 34,079 \\
\hline Derived Cetane & $\mathrm{DCN}$ & 50.5 & 75.4 \\
\hline
\end{tabular}

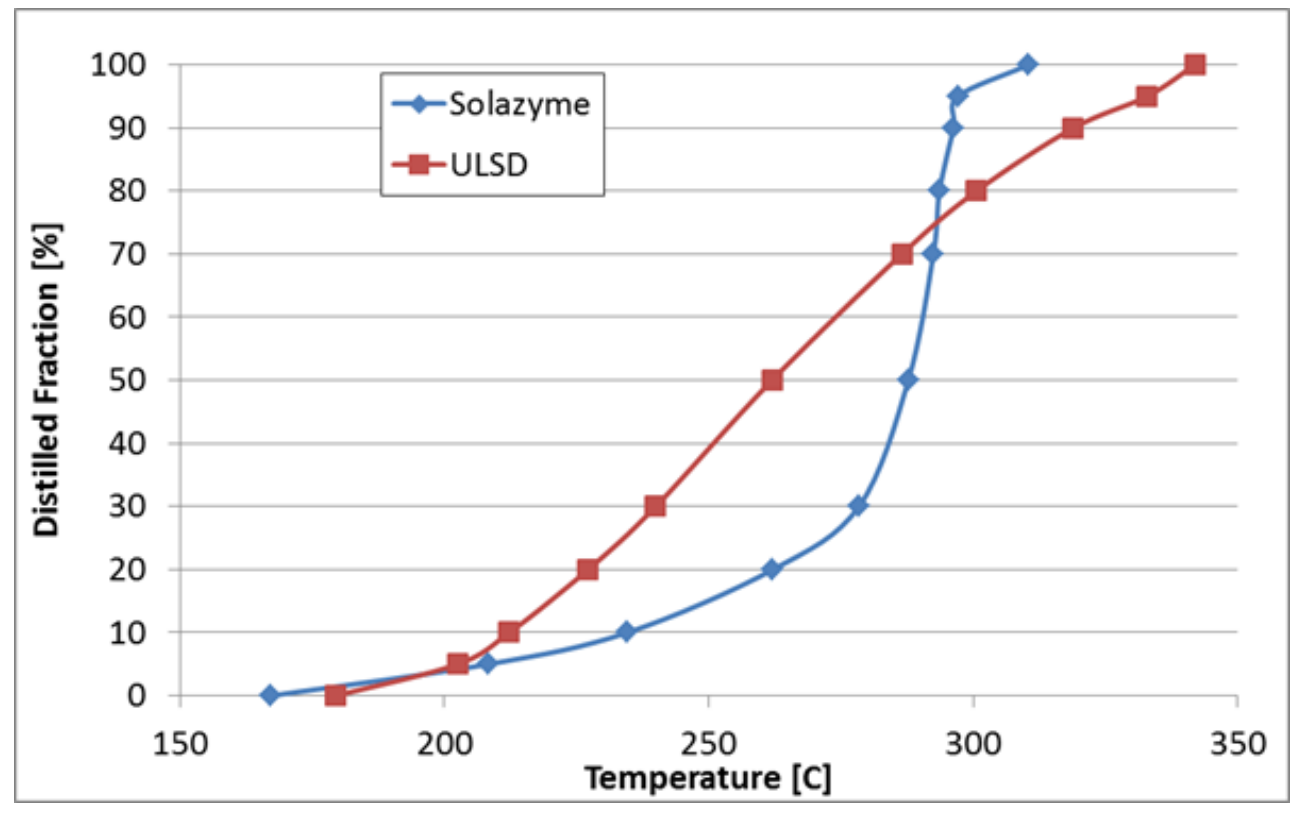

Figure 5. Fuel distillation profile

Figure 6 shows the fuel density and volumetric lower heating values (LHVs) for both test fuels, as well as reference values for two additional sources for comparison. The pump fuel for baseline testing was shown to have a biodiesel content of $4.61 \%$, and the heating value and density fell within the diesel family of fuels in the upper right of the graph as expected. The Solazyme renewable diesel test fuel was shown to be on the lighter side of the fuel density spectrum, but it was a good match with the renewable diesel Greenhouse Gas, Regulated Emissions, and Energy 
Use in Transportation (GREET) model (Argonne National Laboratory 2008). With the assumption of constant engine thermal efficiency, the volumetric LHV will be directly related to vehicle fuel economy. The plot shows that renewable diesel has an LHV that is much closer to winter blend diesel No. 1 rather than summer blend No. 2. Our test fuel falls in the middle, but seasonal and regional variation is to be expected.

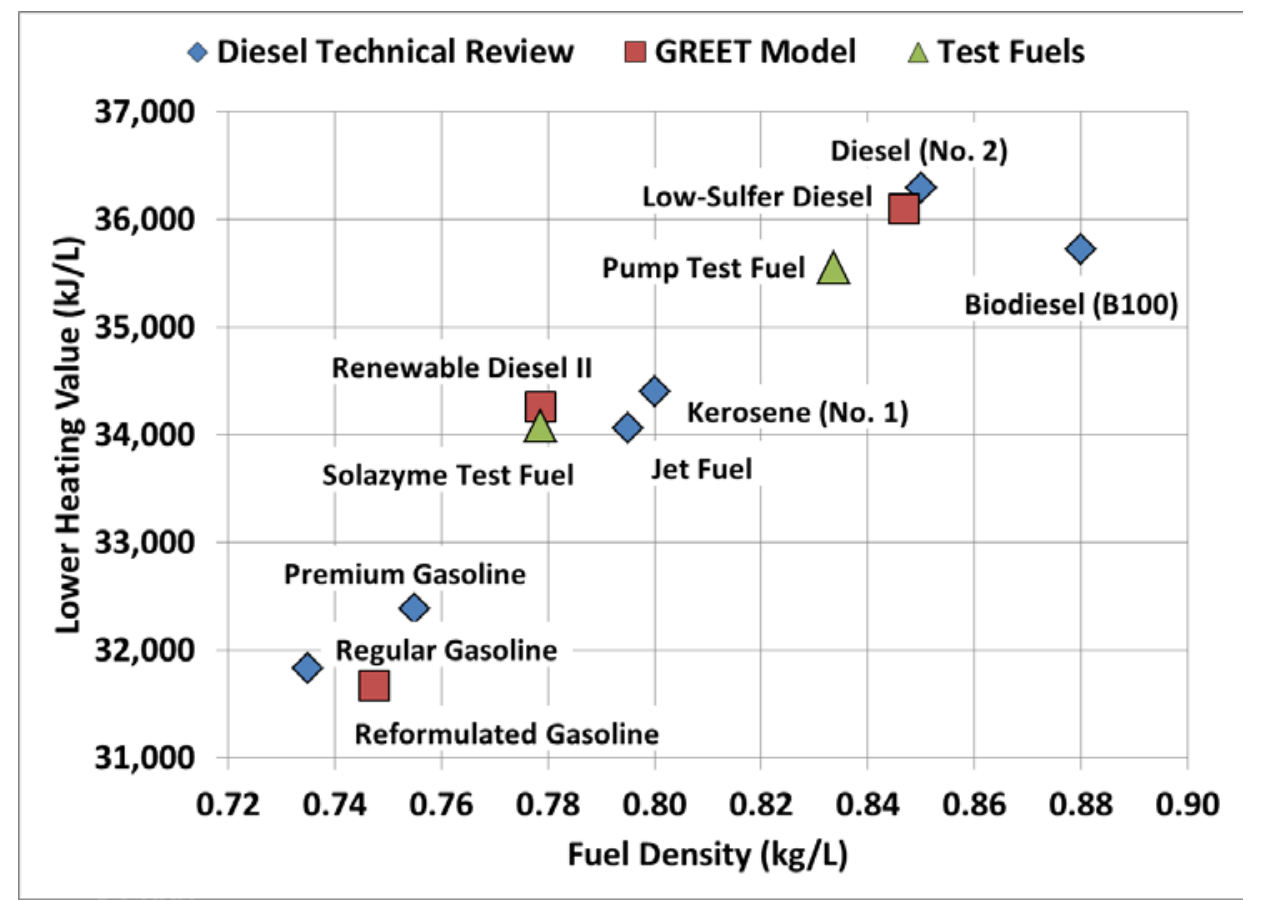

Figure 6. Fuel density and lower heating values compared with reference values

Sources: Chevron (2007), Argonne National Laboratory (2008)

\section{Heavy-Duty Chassis Dynamometer Testing}

Vehicle testing was performed using the heavy-duty chassis dynamometer at NREL's ReFUEL Laboratory. The chassis dynamometer is capable of simulating transient loads on heavy-duty vehicles from 8,000 up to 80,000 pounds at speeds up to 60 miles per hour. To assure the accuracy and consistency of road load simulation, an automated dynamometer warm-up procedure is performed prior to testing until the dynamometer temperatures stabilize and measured parasitic losses in the dynamometer stabilize. After each test run, a loaded coast-down procedure is performed to further ensure stability of vehicle and dynamometer parasitic losses and accurate road load simulation during testing. Vehicle fuel consumption was measured with a gravimetric scale. The fuel returning from the vehicle was cooled with an ambient air-to-liquid heat exchanger to maintain consistent temperatures. The scale mass measurements were recorded in real time along with all of the test data. Engine intake air was conditioned for pressure, humidity, and temperature as well as high efficiency particulate air filtered to eliminate background particulate matter. Engine intake air was maintained at $20^{\circ} \mathrm{C}$ with a dew point of $12^{\circ} \mathrm{C}$, which has a relative humidity of approximately $50 \%$. The intake air pressure was maintained at a slight positive gage pressure of about 4-5 millibar above ambient pressure, which is typically around 840 millibar for Denver. Vehicle exhaust was diluted via a constant volume sample full dilution system. The constant volume sample system relies on sonic flow 
across orifices to measure exhaust flow rates and dilution ratios. The dilution air for the exhaust is supplied by the same system that supplies air to the intake of the engine. Gaseous emissions were measured with a Horiba MEXA 7100DEGR Bench.

Cold-start and warm-up tests have been omitted from the results shown in Figures 7-10. Each data point is an average of a minimum of three consecutive hot-start tests with a 20-minute soak period in between. Error bars on all figures indicate 95\% confidence intervals. Figure 7 shows the measured gravimetric fuel consumption for all tests. The solid bars indicate tests conducted on the day-cab tractor, and the patterned bars indicate tests conducted on the package car. Although three cycles were selected for the package car, only one (NY Composite) was completed. For the tractors, HWFET and HHDDT exhibited similar results cycle to cycle while the Commuter cycle showed an increase in fuel consumption, likely due to the short duration of the test and therefore higher weighting of acceleration up to speed relative to cruising. For the package cars, the NY Composite cycle (a more aggressive low-speed test, which would typically increase fuel consumption) resulted in lower overall fuel consumption-variances in the vehicle’s weight and aerodynamic drag properties more than make up the difference.

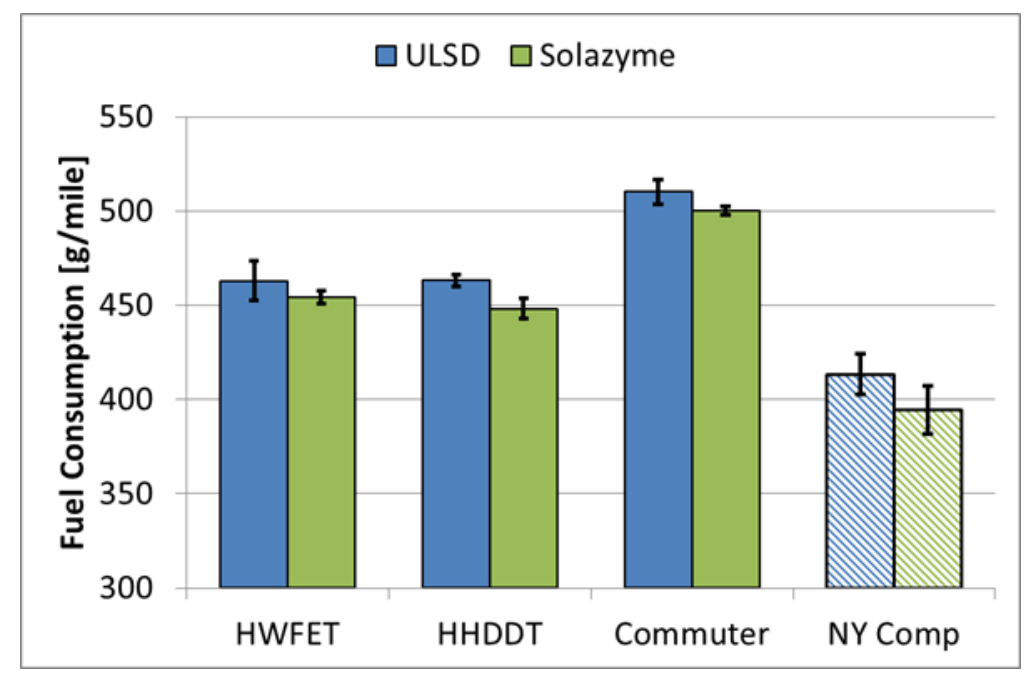

Figure 7. Fuel consumption

As noted in the fuel properties results, typically a decrease in fuel consumption would result in increased fuel economy as the two are inversely proportional. However, in this case, the density of the Solazyme renewable diesel fuel is lower than ultra-low sulfur diesel (ULSD) by a greater ratio than the gains in fuel consumption, resulting in an increased volumetric fuel consumption and lower fuel economy. The fuel economy results are shown in Figure 8. 


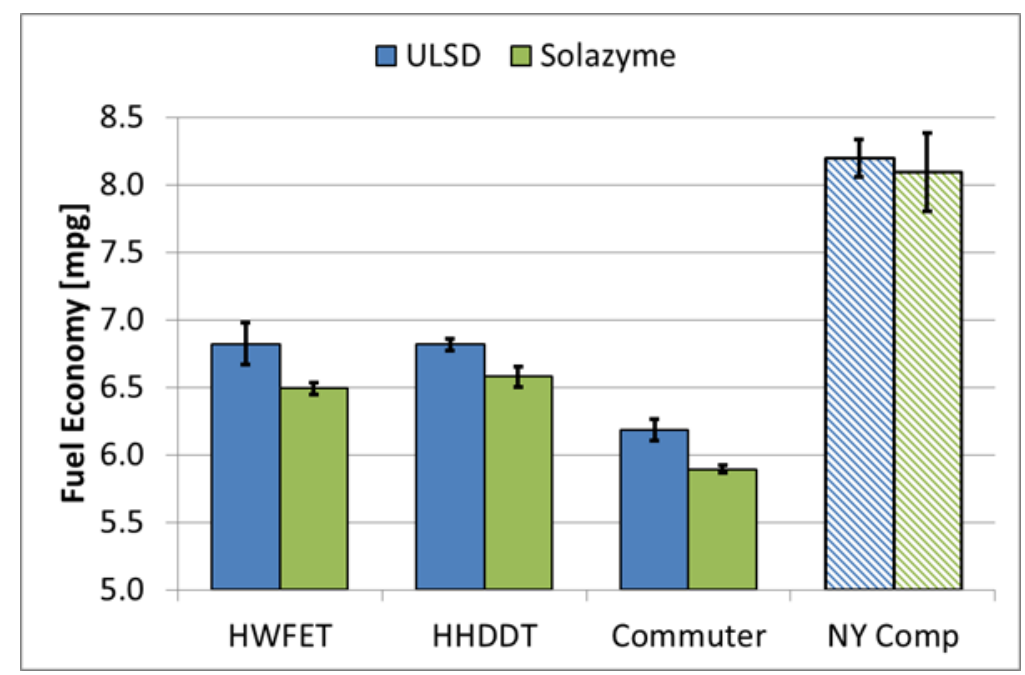

Figure 8. Fuel economy

Figure 9 shows the relative changes in tailpipe $\mathrm{CO}_{2}$ emissions, fuel consumption, and fuel economy when switching from ULSD to Solazyme renewable diesel fuel for the three day-cab tractor tests. Variability in the NY Composite test cycle did not result in a statistically significant difference and was therefore omitted. All three cycles show a consistent $4.2 \%$ decrease in tailpipe $\mathrm{CO}_{2}$ emissions. Fuel consumption and economy showed more variability from cycle to cycle, but both trended as expected with Solazyme's higher mass-based and lower volume-based heating values due to its lower density.

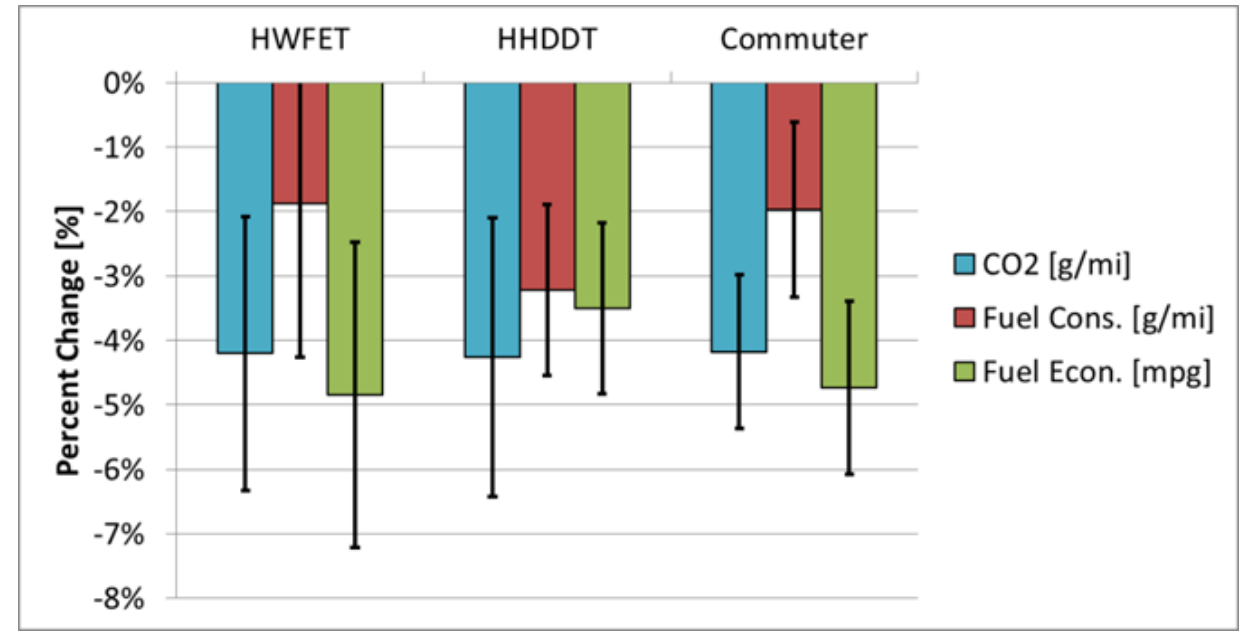

Figure 9. Percent change in $\mathrm{CO}_{2}$ emissions, fuel consumption, and fuel economy for renewable diesel compared to ULSD

Figure 10 shows average brake-specific tailpipe nitrogen oxide $\left(\mathrm{NO}_{\mathrm{x}}\right)$ emissions for all cycles tested. Shown for reference are the applicable family emission limit (FEL) and not-to-exceed (NTE) $\mathrm{NO}_{\mathrm{x}}$ limits for the two different vehicles. All cycles on both fuels are shown to be in compliance. The 2015 day-cab tractor conforms to a $0.2 \mathrm{~g} / \mathrm{bhp}-\mathrm{hr} \mathrm{NO}_{\mathrm{x}}$ emissions standard and likely shows greater variability because the selective catalyst reduction (SCR) system introduces extra variables. Tailpipe emissions can be affected by engine-out conditions as well as SCR temperature, feed gas composition, and urea dosing strategy. The absolute emissions levels are so low that even a small amount of slip past the catalyst can have a large percentage impact. The 
2009 package car conforms to a $1.2 \mathrm{~g} / \mathrm{bhp}-\mathrm{hr} \mathrm{NO}_{\mathrm{x}}$ emissions standard without using an SCR system. $\mathrm{NO}_{\mathrm{x}}$ emissions on the package car are primarily managed via exhaust gas recirculation. Absolute-measured $\mathrm{NO}_{\mathrm{x}}$ emissions are roughly 10 times higher, but the package car demonstrated a $4.1 \%$ reduction in $\mathrm{NO}_{\mathrm{x}}$ emissions when switching to Solazyme fuel. However, to fully quantify these changes with reduced variability, an engine test stand may be preferred over full vehicle chassis testing.

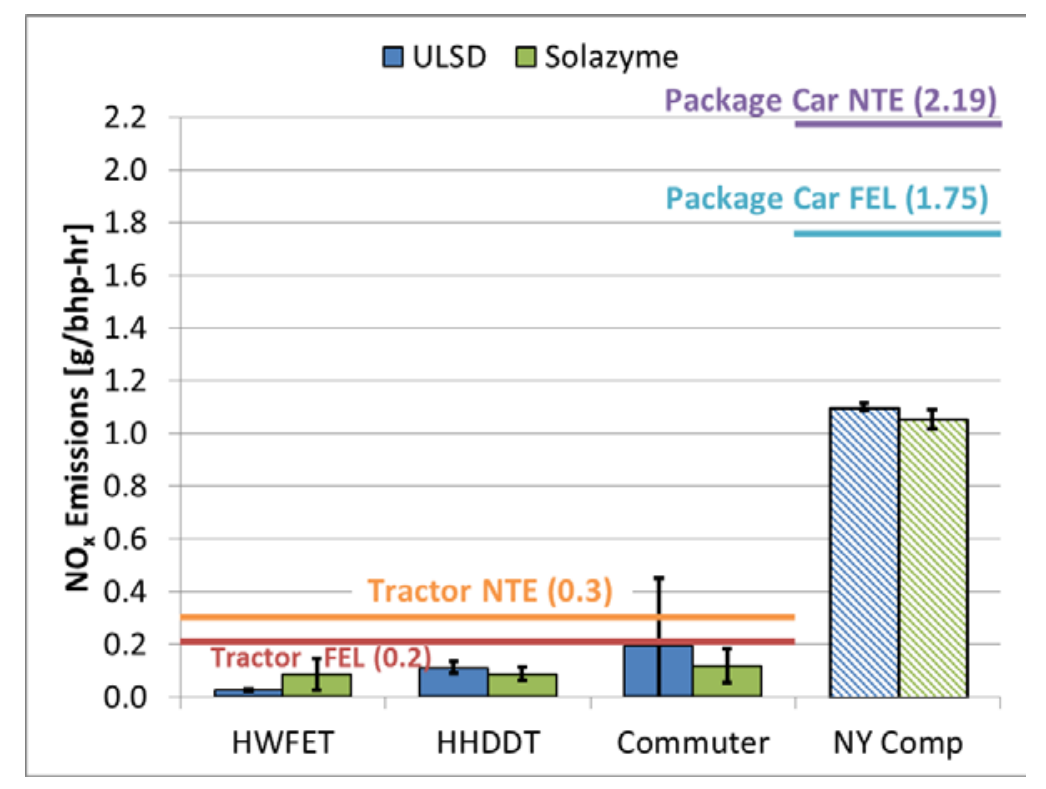

Figure 10. $\mathrm{NO}_{\mathrm{x}}$ emissions

\section{Conclusions}

A three-week in-field data collection period on six day-cab tractors and six package cars yielded 170 usable days of real-world vehicle operation that were used to select representative standard cycles for further testing. Fuel economy and emissions tests at NREL's ReFUEL Laboratory showed that, in general, when switching from conventional petroleum diesel to renewable diesel, the thermal efficiency of a cycle remains relatively constant and observed changes in tailpipe $\mathrm{CO}_{2}$, fuel consumption, and fuel economy are primarily driven by changes in fuel properties such as the hydrogen-to-carbon ratio, density, and LHV. The vehicles tested with Solazyme fuel showed a consistent $4.2 \%$ reduction in tailpipe $\mathrm{CO}_{2}$, but a 3.5\%-4.8\% reduction in fuel economy compared with local pump diesel. This is consistent with the $4.2 \%$ lower volumetric LHV of the Solazyme fuel compared to the pump diesel (Table 4). However, pump diesel values could vary regionally and seasonally based on local pump fuel blending and composition. The UPS package car tested on Solazyme fuel also demonstrated a $4.1 \% \mathrm{NO}_{\mathrm{x}}$ reduction. $\mathrm{NO}_{\mathrm{x}}$ emissions from the UPS SCR-equipped tractor were an order of magnitude lower than the package car but showed some variability in results from cycle to cycle. To reduce test variability, especially with SCRequipped engines, and resolve small $\mathrm{NO}_{\mathrm{x}}$ fluctuations, an engine test stand may be more suitable than full vehicle chassis testing. 


\section{References}

Argonne National Laboratory. 2008. "Transportation Fuel Cycle Analysis Model, GREET 1.8b." Argonne, IL: Argonne National Laboratory. Released September 5, 2008.

https://greet.es.anl.gov/.

Chevron. 2007. Diesel Fuels Technical Review. https://www.chevron.com/-

/media/chevron/operations/documents/diesel-fuel-tech-review.pdf.

UPS. 2015. “UPS Makes Substantial Move to Renewable Fuels.” July 29, 2015.

https://www.pressroom.ups.com/pressroom/ContentDetailsViewer.page?ConceptType=PressRel eases\&id=1438111777421-236. 